\title{
The Impact of Carbon Tax Policy on the Carbon Emission Reduction and Profit
}

\author{
Hongyan $\mathrm{Hu}^{*}$, Wenlong Zhou \\ School of Economics and Management, Beijing Jiaotong Universty, Beijing 100044, \\ China \\ E-mail: huhongyan123@sohu.com,zwl427@163.com
}

\begin{abstract}
Carbon tax is one of the most common carbon emission regulation policies, manufactures and customers must incorporate it in their pricing and purchase decisions. This paper examined the impact of the different carbon tax policies on the carbon emission and their profits. This problem is formulated as a Stackelberg game, the manufacture is the leader, the retailer is the follower, the manufacture's optimal pricing decision and the customer purchase decisions are derived. Then the impact of carbon tax policy on these decisions and the carbon emission and the profits is also investigated. We found that carbon emission will be reduced if the carbon tax is absorbed by the customers and the carbon footprints of unit product is relative high compared with the setting that the carbon tax is absorbed by the manufacture and the carbon footprints of unit product is relative low.
\end{abstract}

Keywords: Carbon tax; Stackelberg game; pricing decision; Carbon emission

\section{Introduction}

Manufactures, retailer and customers face different carbon emission regulation policies such as strict carbon caps, carbon tax, carbon emission trade, and carbon offsets. Carbon tax is one of the most common policies. It means one should pay for his product's carbon emission. In practice, the carbon tax may be absorbed by the manufacture or the customers.

A natural question is that which case can reduce more carbon emission. In this paper we will address this problem. We consider a supply chain consisting of a manufacture and a retailer, the manufacture will decide the wholesale price. The retailer decides the retail price. The customers decide whether to buy.

Our work is elated to carbon emission policies, such as cap-and-trade, carbon tax, government subside, and others. Fischer (2003) found that unfettered trade between ratebased and cap-and-trade always raises combined emissions, except when product markets are related in some particular ways. They also found that a range of combinations of tighter allocat on can improve situations in both sectors with trade while holding emissions constant. Griil hand Taschini (2011) examined the key design mechanisms of existing and proposed cap-and-trade markets. They quantified the advantages and disadvantages of the proposed hybrid schemes. Hua et al., (2011) studied the firms' optimal carbon footprints in inventory management with carbon emission trade, derived the optimal order sizing, and examined the impact of carbon emission trade on the decisions. Hua et al., (2011) further investigated the optimal order lot sizing and pricing with carbon trade based on the EOQ model, and examined the impact of the carbon emission trade on the order lot sizing and pricing. Bristow et al., (2010) represented a novel application of stated preference techniques to explore the 
influence of key design attributes on the acceptability of a personal carbon trading scheme. They found that the best scheme designs could be acceptable to a majority of respondents.

Our work is also related to the impact of carbon tax. There are some researches on this topic. Some papers dealt with strategic decisions in a supply chain with carbon emission trade. Lin and $\mathrm{Li}$ (2011) estimated the real mitigation effects of the five north European countries (Denmark, Finland, Sweden, Netherlands and Norway) using the difference-indifference method. They found that carbon tax in Finland imposes a significant and negative impact on the growth of its per capita $\mathrm{CO}_{2}$ emissions, and the effects of carbon tax in Denmark, Sweden and Netherlands are negative but not significant. Because of the tax exemption policies on certain energy intensive industries in these countries, the mitigation effects of carbon tax are weakened. He et al., (2012) compared the cap-and-trade and carbon tax policies in a generation expansion planning framework using a bi-level optimization approach, the efficiency is measured by seven criteria: average emissions price, actual emissions, renewable energy portfolio, total generation, and total profit of Gencos and grid owner, economic welfare, and emissions adjusted economic welfare. The author integrated cap-and-trade and four variations of carbon tax policies in a gane-theoretic based generation expansion planning model, and assessed their impacts on ney investment in renewable energy generation capacity. Lee et al., (2013) analyzed the quantitative effects of a maritime carbon tax on global economy, and the impact of the carbon tax on containerizable commodities. They found that imposing a maritime carbon tax will not lead to a significant economic impact. Jiang and Klabjan (2012) studied the Goint production capacity and investment decisions with stochastic deman under command-and-control and market-based regulations such as carbon tax and cap=and- trade Benjaafar et al., (2013) incorporated different carbon emission policies including carbon tax and cap-and-trade into operational decision-making using relatively simple and widely used models, and examined how the values of carbon emission parameters as well as the parameters of regulatory emission control policies affect cost and emissions. These models were used to study the extent to which carbon reduction requirements can be addressed by operational adjustments, as an alternative (or a supplement) to costly investments it carbon-reducing technologies. By employing a local manufacturer by offsetting the probable higher total logistics and production costs, Choi (2013) examined how to properly designed carbon footprint taxation scheme in a QR system to enhance environmental sustainability. The author illustrated how the carbon footprint taxation scheme affects the optimal choice of sourcing decision. The author found that a properly designed carbon footprint taxation scheme not only can successfully entice the fashion retailer to soufce from a local manufacturer, but also lead to a lower level of risk for the fashion retailer Asbi et al., (2013) introduced carbon emission constraints, i.e., carbon emission trade, in multisourcing lot-sizing problems. Four types of constraints are proposed and analyzed in the single-item uncapacitated lot-sizing problem. Toptal et al., (2014) examined the joint inventory replenishment and emission reduction investment decisions under different emission regulations, including carbon tax and cap-and-trade. They extended the EOQ model to consider carbon emissions reduction investment option under carbon cap, tax and cap-and-trade policies. They found that carbon emission reduction investment opportunities reduce carbon emissions while reducing costs. Cachon (2014) discusses the impact of the new objective of reducing carbon footprints on supply chain operations and structures, the author found that only minimizing exclusively operating costs may substantially increase emissions relative to the minimum level of emissions, and carbon pricing is not effective to reduce emissions. The most effective measure is to improve consumer fuel efficiency while an improvement in truck fuel efficiency has a marginal impact on total emissions. Diabat et al., (2013) examined a multiechelon multicommodity closed- 
loop facility location problem with carbon emissions trade, model and algorithm were provided, in which the company may incur costs if the carbon cap assigned by regulatory agencies is lower than the total emissions, or gain profit if the carbon cap is higher than the total emissions.

The rest of this paper is organized as follows. Sections 2 and 3 examine the retailer and manufacture's model when the carbon tax is absorbed by the manufacture and by the customers, respectively, and derives the optimal pricing decisions, and examine the impact of the carbon tax per unit on the manufacture's optimal wholesale price, the retailer's optimal retail price and the customer's demand. Section 4 is dedicated to examine the impact of different carbon emission tax on the manufacture and retailer's decisions and profits. And Section 5 concludes the paper.

\section{The Model when the Carbon Tax is Absorbed by the Manufacture}

In this section, we consider a supply chain consisting of a manufacture and aretailer, the manufacture should decide the optimal wholesale price, the retailer should decide his optimal retail price. We formulate this problem as a Stackelberg game, i.e., the nanufacture is the leader, the retailer is the follower. We discuss two cases, e., manufacture absorbs the carbon tax, and retailer absorbs the carbon tax. We derive the optimal wholesale price and profit for manufacture, and the optimal retail price and profit for letailer. We also examine the impact of the carbon tax per unit on the manufacture's optimal wholesale price, the retailer's optimal retail price and the customer's demand.

\subsection{Assumptions and Notation}

The following assumptions and notation are used in this paper.
$\lambda:$ the carbon footprints of unit produc
$Q$ : the manufacture's carbon emission,
$c$ : the production $\cos \theta$ f unit product,
$r$ : the carbon tax per unit (ton),
$w$ : the wholesale price;
$p$ : the retail price $(p>w>C)$
$d$ : the customer demand.
$\pi^{m}$ : the manufacture sprofit;
$\pi^{r}:$ the retailer's profit;

Following most of the related literature, we assume that the customer demand function decreases in the retail price, i.e., $d=a-b p$, where $a$ and $b$ are positive constants.

The manufacture's carbon emission is

$$
Q=\lambda d=a \lambda-b \lambda p
$$

To simplify, we denote 1 at the lower right corner of all the notions in this model and 2 in the next model, for example, $Q_{1}, Q_{2}$.

We also suppose that $d=a-b(c+2 r \lambda)>0$, i.e., when $p=c+2 r \lambda$, the customer demand is positive, which is not strict in practice.

\subsection{The Retailer's Decision}

Given the manufacture's wholesale price $w$, the retailer should decide his retail price $p$ to maximize his profit. The retailer's profit is 


$$
\pi_{1}^{r}=\left(p_{1}-w_{1}\right) d=\left(p_{1}-w_{1}\right)\left(a-b p_{1}\right)
$$

Let $\frac{d \pi_{1}^{r}}{d p_{1}}=0$, we have the retailer's retail price and the customer's demand as follows.

$$
\begin{aligned}
& p_{1}=\frac{a+b w_{1}}{2 b} \\
& d_{1}=\frac{a-b w_{1}}{2}
\end{aligned}
$$

From (2)-(4), we have

$$
\pi_{1}^{r}=\frac{\left(a-b w_{1}\right)^{2}}{4 b}
$$

Obviously, the retailer's retail price and the customer's demand, and the retailer's profit only depend on the wholesale price $w_{1}$, which are the same as the related iterature.

\subsection{The Manufacture's Decision}

Given the optimal retailer's respond function, the manufacture should decide his wholesale price. The manufacture's profit is

$$
\pi_{1}^{m}=\left(w_{1}-c\right) d_{1}-r 2 d=\left(w_{1}-c-\lambda\right) \frac{a-b w_{1}}{2}
$$

Let $\frac{d \pi_{1}^{m}}{d w_{1}}=0$, we have the following theorem.

Theorem 1. The manufacture's optimal wholesale price is

$$
w_{1}^{*}=c+r \lambda+\frac{a-b c-b r \lambda}{2 b}
$$

Because the proof is simpy, it is omitted. From (7), we see that the wholesale price includes three parts, one is production cost $c$, and carbon tax per unit product $r \lambda$, and the third one is the marginal profit $\frac{a-b c-b r \lambda}{2 b}$. The marginal profit will decrease with increasing the carbon tax per unit.

Notice that from (7), $\frac{d w_{1}^{*}}{d r}=\frac{\lambda}{2}>0$, we have the following theorem.

Theorem 2. $\frac{d w_{1}^{*}}{d r}>0$.

Theorem 2 indicates that the manufacture's optimal wholesale price will increase with increasing the carbon tax per unit, which is straightforward.

From Theorem 1, we have the following Theorem 3.

Theorem 3. The retailer's optimal retail price and the customer's demand are

$$
p_{1}^{*}=c+r \lambda+\frac{3 a-3 b c-3 b r \lambda}{4 b}
$$




$$
d_{1}^{*}=\frac{a-b c-b r \lambda}{4}
$$

Substituting (7) into (3) and (4), we can prove Theorem 3, so the proof is omitted. From (8) and (9), we have $p_{1}^{*}>w_{1}^{*}>c+r \lambda$, which satisfies our assumption. And the manufacture's marginal profit is $w_{1}^{*}-(c+r \lambda)=\frac{a-b c-b r \lambda}{2 b}$, the retailer's marginal profit is $p_{1}^{*}-w_{1}^{*}=\frac{a-b c-b r \lambda}{4 b}$, which is half of the manufacture's. This result is the same as Hu and Zhou (2014). The customer's demand is the retailer's marginal profit times the demand elastic coefficient $b$.

From Theorem 3, we have the following Theorem 4.

Theorem 4. $\frac{d p_{1}^{*}}{d r}>0, \frac{d d_{1}^{*}}{d r}<0$.

Theorem 4 indicates that the retailer's optimal retail price will increase and the customer's demand will decrease with increasing the carbon tax per unit.

Substituting (9) into (1), (7) and (8) into (5), (7) into (6), we have

$$
\begin{aligned}
& Q_{1}^{*}=\frac{a \lambda-b c \lambda-b r \lambda^{2}}{4} \\
& \pi_{1}^{r^{*}}=\frac{a c-b r \lambda^{2}}{16 b} \\
& \pi_{1}^{m^{*}}=\frac{(a-b c-b r \lambda)^{2}}{8 b}
\end{aligned}
$$

(10)-(12) show that when the carbon tax is absorbed by the manufacture, the manufacture's carbon emission, profit and the retailef's profit depend on the carbon footprints of unit product and the carbon tax per unit.

\section{The Model yhen the Carbon Tax is Absorbed by the Customers}

If the customers absorb the carbon tax, then the demand is

$$
d_{2}=a-b\left(p_{2}+r \lambda\right)=a-b r \lambda-b p_{2}
$$

\subsection{The Retailer's Decision}

The retailer's profit is

$$
\pi_{2}^{r}=\left(p_{2}-w_{2}\right) d_{2}=\left(p_{2}-w_{2}\right)\left(a-b r \lambda-b p_{2}\right)
$$

Let $\frac{d \pi_{2}^{r}}{d p_{2}}=0$, we have the retailer's retail price and the customer's demand are

$$
\begin{aligned}
& p_{2}=\frac{a-b r \lambda+b w_{2}}{2 b} \\
& d_{2}=\frac{a-b r \lambda-b w_{2}}{2}
\end{aligned}
$$

From (14)-(16), we have 


$$
\pi_{2}^{r}=\frac{(a-b r \lambda-b w)^{2}}{4 b}
$$

\subsection{The Manufacture's Decision}

The manufacture's profit is

$$
\pi_{2}^{m}=\left(w_{2}-c\right) d_{2}-r \lambda d_{2}=\left(w_{2}-c-r \lambda\right) \frac{a-b r \lambda-b w_{2}}{2}
$$

Let $\frac{d \pi_{2}^{m}}{d w_{2}}=0$, we have the following theorem.

Theorem 5. The manufacture's optimal wholesale price is

$$
w_{2}^{*}=\frac{a+b c}{2 b}
$$

Because the proof is simply, it is also omitted.

From Theorem 5, we have the following theorem.

Theorem 6. $\frac{d w_{2}{ }^{*}}{d r}=\frac{d w_{2}{ }^{*}}{d \lambda}=0, \frac{d w_{2}{ }^{*}}{d c}=\frac{1}{2}$.

Theorem 6 indicates that the manufacture's oftimal whele@g price has nothing to do with the carbon footprints of unit product and the carbon tax per unit. It only depends on the production cost of unit product, and when the production cost increases one unit, the manufacture's wholesale price will increase half of ône unit.

From Theorem 3, we have the following Theorem 7 .

Theorem 7. The retailer's optimaletail price and the customer's demand are

$$
\begin{aligned}
& Q p_{2}^{*}=\frac{3 a+b c-2 b r \lambda}{4 b} \\
& d \int_{2}^{*} \frac{a c-2 b r \lambda}{2}
\end{aligned}
$$

The proof is omitted Obviously, $p_{2}^{*}>c+r \lambda$, i.e., $a-b c-2 b r \lambda>0$, this is why we add the assumption that $d=a-b(c+2 r \lambda)>0$, then we can prove that $p_{2}^{*}>w_{2}^{*}>c+r \lambda$, which satisfies our assumption. And the manufacture's marginal profit is $w_{2}^{*}-(c+r \lambda)=\frac{a-b c-2 b r \lambda}{2 b}$, the retailer's marginal profit is $p_{2}^{*}-w_{2}^{*}=\frac{a-b c-2 b r \lambda}{4 b}$, which is half of the manufacture's.

From Theorem 7, we have the following Theorem 8.

Theorem 8. $\frac{d p_{2}{ }^{*}}{d r}<0, \frac{d d_{2}^{*}}{d r}<0, \frac{d p_{2}^{*}}{d c}=\frac{c}{4}, \frac{d d_{2}^{*}}{d c}=-\frac{c}{2}$.

Theorem 8 indicates that the retailer's optimal retail price and the customer's demand will decrease with increasing the carbon tax per unit. The retailer's optimal retail price will increase one fourth of the production cost and the customer's demand will decrease half of the production cost with increasing the production cost one unit.

From the above equations, we have 


$$
\begin{gathered}
Q_{2}^{*}=\frac{a \lambda-b c \lambda-2 b r \lambda^{2}}{2} \\
\pi_{2}^{r^{*}}=\frac{(a-b c-2 b r \lambda)^{2}}{16 b} \\
\pi_{2}^{m^{*}}=\frac{(a-b c-2 b r \lambda)^{2}}{8 b} \\
Q_{1}^{*}=\frac{a \lambda-b c \lambda-b r \lambda^{2}}{4}
\end{gathered}
$$

(22)-(24) also show that when the carbon tax is absorbed by the customers, the manufacture's carbon emission, profit and the retailer's profit depend on the carbon footprints of unit product and the carbon tax per unit.

\section{The Impact of Different Carbon Tax Policies}

In this section, we will examine the impact of different carbon emission tax on the manufacture and retailer's decisions and profits.

From Sections 2 and 3, we have the following theorem.

Theorem 9. $p_{1}^{*}>p_{2}^{*}, w_{1}^{*}>w_{2}^{*}, \pi_{1}^{r^{*}}>\pi_{2}^{r^{*}}, \pi_{1}^{m^{*}}>\pi_{2}^{m^{*}}$.

From the above analysis and notice that $a-b c-2 b r \geqslant 0$, the results are straightforward, so the proof is omitted.

Theorem 9 states that compared with the setting that manufacture absorbs the carbon tax, wholesale price, retail price and the manufacture's profit, the retailer's profit decrease when customers absorb the carbon tax, which indicates that it is better to adopt the second carbon tax policy.

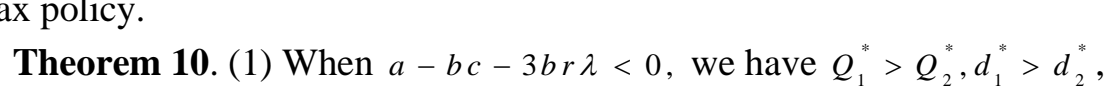

(2) When $a-b<3 b r y>0$, we have $Q_{1}^{*}<Q_{2}^{*}, d_{1}^{*}<d_{2}^{*}$.

Proof. From (8) and (20), we have $d_{1}^{*}-d_{2}^{*}=-\frac{a-b c-3 b r \lambda}{4}$, and from (10) and (22), we have $Q_{1}^{*}-Q_{2}^{*}=-\frac{a \lambda}{4}$, so the results hold.

Theorem 10 states that the demand in the second case may be greater than that in the first case, which delpends on the sign of $a-b c-3 b r \lambda$, which indicates that our intuition that the demand in the second case is less is not true although the customer should bear the carbon tax. Theorem 10 also tells us that when $a-b c-3 b r \lambda<0$, the government should tax the customers and when $a-b c-3 b r \lambda>0$, the government should tax the manufacture, then the carbon emission will decrease by $\frac{|a-b c-3 b r \lambda| \lambda}{4}$. In other words, if the carbon footprints of unit product is relative high, the government should tax the customers, otherwise, the government should tax the manufacture. 


\section{Conclusion}

In this paper, we examined the impact of carbon tax policies on the carbon emission reduction. The problem was formulated as a Stackelberg game, the manufacture is the leader, and the retailer is the follower. We derived the optimal decisions for the manufacture and retailer. Then the impact of carbon tax policy on these decisions and the carbon emission and the profits is also investigated. We also compared the two settings, i.e., manufacture absorbs the carbon tax and customers absorb the carbon tax.

We found that compared with the setting that manufacture bears the carbon tax, the carbon emission decreases when customers absorb the carbon tax and the carbon footprints of unit product is relative high, otherwise, the carbon emission decreases when manufacture absorb the carbon tax and the carbon footprints of unit product is relative low. And furthermore, the retail price, the wholesale price, the manufacture's profit and the retailer's profit will decrease. However, the demand when customers absorb the carbon tax may increase compared with the setting that manufacture absorbs the carbon tax.

There are some other future research directions. For example we suppose that the demand function is linear in the price in this paper, other demand functions such as the exponential demand, the iso-price-elastic demand, and the Logit demand are deserved to incorporate to the model. Or we can consider the demand function is stochastic or multi-product demand. We can also consider other supply chain construct, such as dual-chaniel supply chain, maketo-order supply chain, make-to-assembly supply chain, dual sourcing supply chain, three-tier supply chain, and others.

\section{References}

[1] N. Asbi, S. Dauzère-Pérès and S. Kedad-Sidhoum, "Lot sizing with carbon emission constraints", European Journal of Operational Research, 22 :55-61, (2013)

[2] A. L. Bristow, M. Wardman, A. M., Zanni and P. K. Chintakayala, "Public acceptability of personal carbon trading and carbon tax", Ecological Economics. vol 69, no. 9, (2010), pp. 1824-1837.

[3] S. Benjaafar, Y. Z. Li and M Daskin, "Carbon footprint and the management of supply chains: insights from simple models", IEEE transactions on automation science and engineering, vol. 10, no. 1, (2013), pp. 99-116.

[4] G. Cachon, "Retain store density and the cost of greenhouse gas emissions", Accepted by Management Science, (2014).

[5] T. M. Choi, " ocal sourcing and fashion quick response system: The impacts of carbon footprint tax", Transportation Research Part E. Logistics and Transportation Review, vol. 55, (2013), pp. 43-54.

[6] A. Diabat, 1.Abdallah and A Al-Refaie, "Strategic closed-loop facility location problem with carbon market trading”, IEEE Transactions on Engineering on Management, vol. 60, vol. 2, (2013), pp. 398-408.

[7] C. Fischer, "Combining rate-based and cap-and-trade emissions policies", Climate Policy, vol. 3, no. 2, (2003), pp. S89-S103.

[8] G. Grüll and L. Taschini, "Cap-and-trade properties under different hybrid scheme designs", Journal of Environmertal Economics and Management, vol. 61, no. 1, (2011), pp. 107-118.

[9] Y. Y. He, L.Z. Wang and J. H. Wang, "Cap-and-trade vs. carbon taxes: A quantitative comparison from a generation expansion planning perspective", Computers \& Industrial Engineering, vol. 63, no. 3, (2012), pp. 708-716.

[10]G WHua, T. C. E. Cheng and S. Y. Wang, "Managing carbon footprints in inventory management", vol. 132, (2011), pp. 178-185.

[11] G. W. Hua, H. Qiao and J. Li, "Optimal order lot sizing and pricing with carbon trade", ICEIS 2011 Proceedings of the 13th International Conference on Enterprise Information Systems, (2011), pp. 533-536.

[12] Y. Jiang and D. Klabjan, "Optimal emissions reduction investment under green house gas emissions regulations", Accessed March 2014. http://www.dynresmanagement.com/uploads/ 3/3/2/9/3329212/carbonregulations.pdf.

[13] T. C. Lee, Y. T. Chang and P. T. W. Lee, "Economy-wide impact analysis of a carbon tax on international container shipping", Transportation Research Part A: Policy and Practice, vol. 58, (2013), pp. 87-102.

[14] B. Q. Lin and X. H. Li, "The effect of carbon tax on per capita CO2 emissions", Energy Policy, vol. 39, no. 9, (2011), pp. 5137-5146. 
[15] A. Toptal, H. Özlü and D. Konur, "Joint decisions on inventory replenishment and emission reduction investment under different emission regulations", International Journal of Production Research, vol. 52, no. 1, (2014), pp. 243-269.

\section{Authors}

Hongyan Hu, is a Ph.D condidate, her research interests include supply chain management, low carbon logistics.

Wenlong Zhou, is a Ph.D condidate, his research interests include supply chain management, industry security, and economic policy.

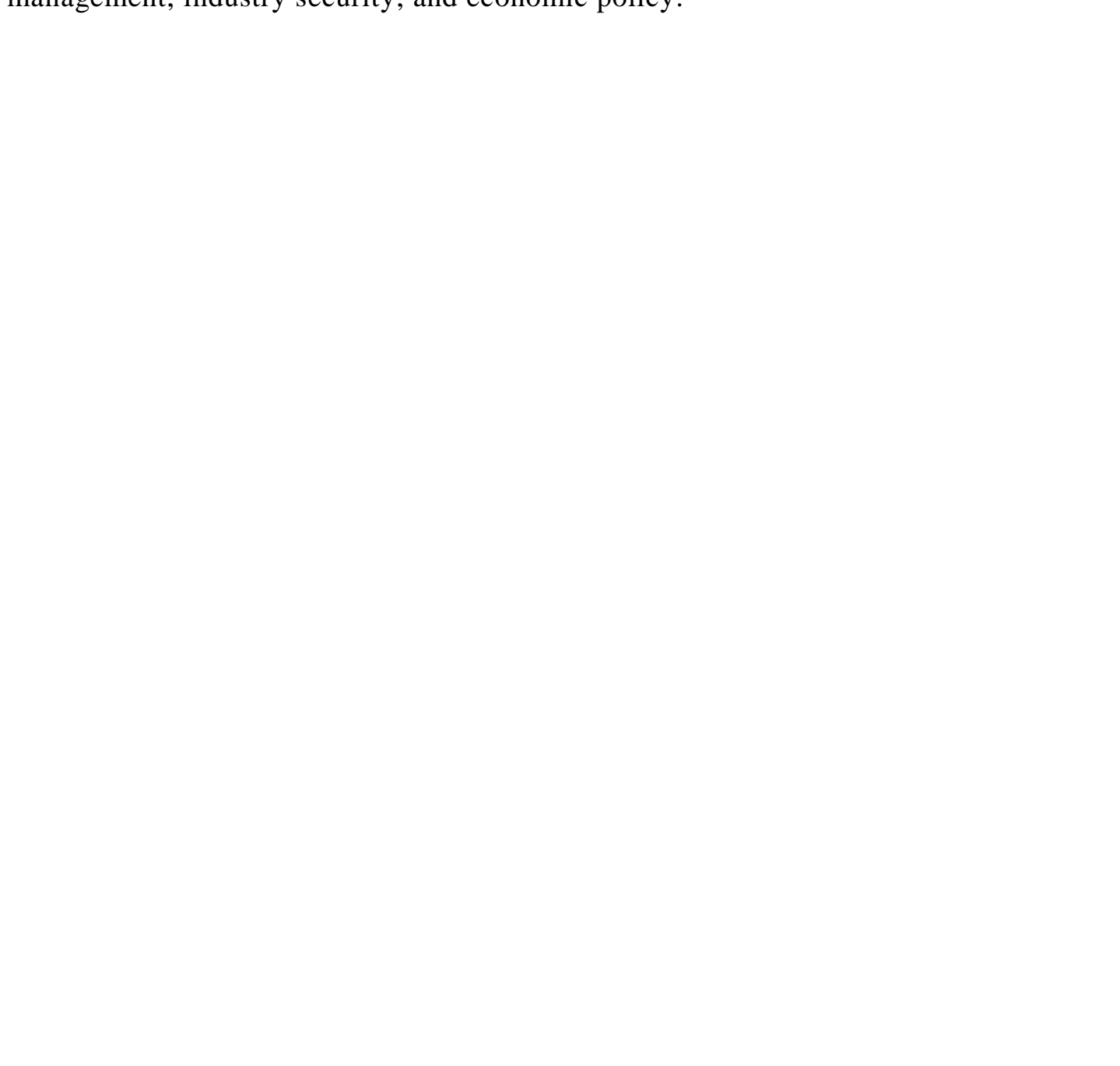


International Journal of Smart Home

Vol.8, No.5 (2014)

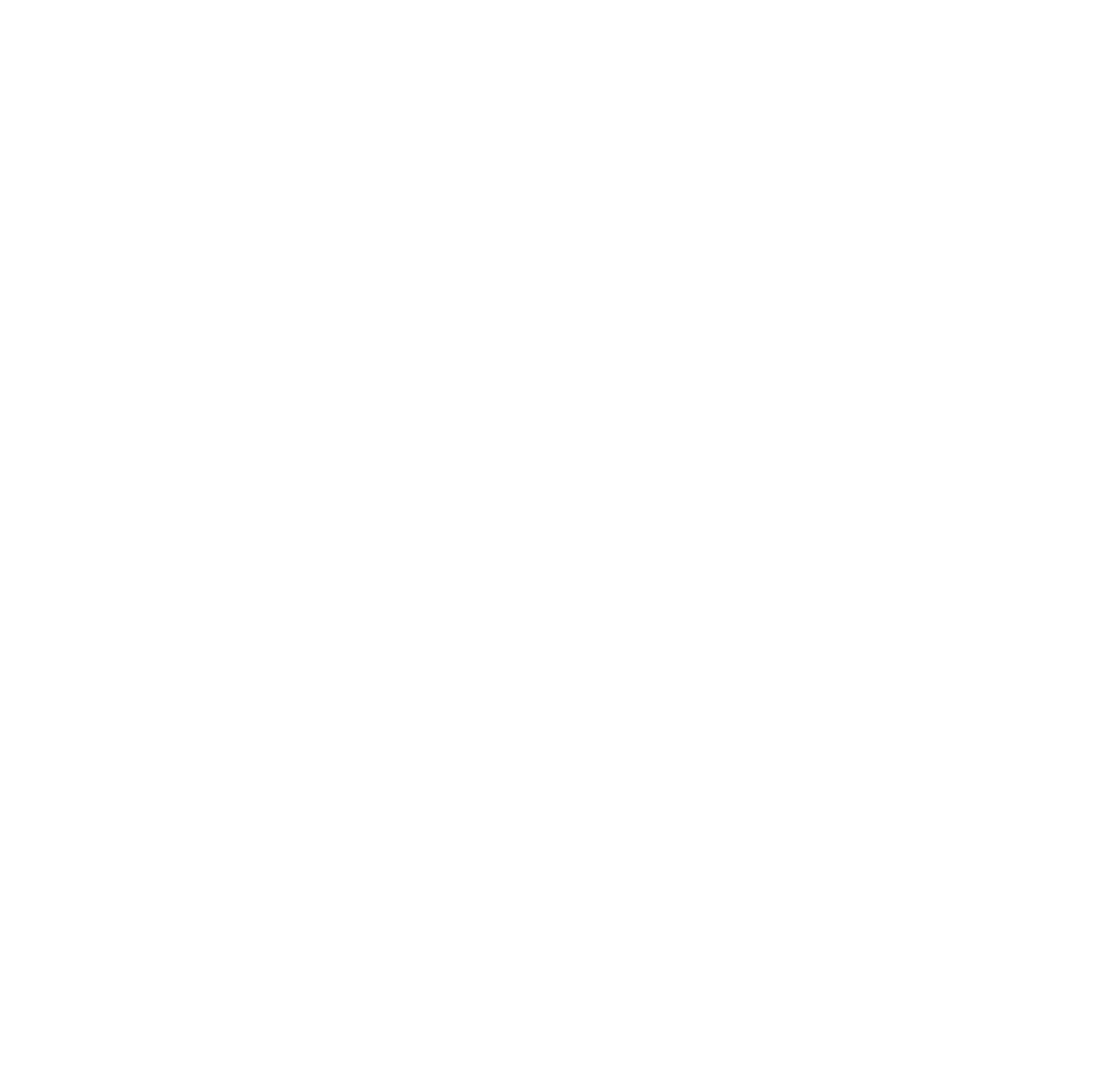

